\title{
LA RELACIÓ ENTRE HISTÒRIA DE LA LLENGUA I HISTÒRIA LITERÀRIA
}

\section{THE RELATIONSHIP BETWEEN THE HISTORY OF LAN- GUAGE AND THE HISTORY OF LITERATURE}

\author{
Jordi Ginebra Serrabou \\ Universitat Rovira i Virgili \\ jordi.ginebra@urv.cat
}

Resum: La relació entre la disciplina història de la llengua i la disciplina història de la literatura ha estat una relació de subordinació, tant des del punt vista conceptual com metodològic. La primera ha estat subordinada a la segona. En aquest article tractem en primer lloc de les circumstàncies i els esdeveniments històrics que han determinat aquesta situació de subordinació: la identificació cultural entre llengua i literatura (però amb la supeditació de la primera a la segona), el naixement de la lingüística romànica (que, paradoxalment, no va afavorir l'autonomia de la història de la llengua) i la desclosa de les cultures nacionals, que també van donar prioritat a la literatura nacional. En segon lloc ens referim a les particularitats metodològiques i pràctiques de les dues disciplines, que també expliquen per què la relació ha anat de la manera com ha anat. I en tercer lloc tractem breument de l'estat actual de la matèria, que fa pensar que la història de la llengua ha tendit a adquirir autonomia en els darrers anys, malgrat que l'objectiu no ha de ser prescindir de la història literària sinó establir-hi els vincles adients.

Paraules clau: història de la llengua, història de la literatura, sociologia de la llengua, lingüística romànica, lingüística catalana.

Abstract: The relationship between the History of Language and the History of Literature as disciplines has been a relationship of subordination, both from a conceptual and a methodological point of view. The first has been subordinated to the second. This article deals, first, with the historical circumstances and events that have determined the situation of subordination: the cultural identification between language and literature (but with the subordination of the first to the second), the birth of Romance linguistics (which, paradoxically, did not favor the autonomy of the history of the language), and the emergence of national cultures, which also gave priority to 
Jordi Ginebra Serrabou

La relació entre història de la llengua i història literària

national literature. Secondly refers to the methodological and practical features of the two disciplines, which also explain why the relationship has gone the way it has gone. And, thirdly, we briefly deal with the current state of the subject, which suggests that the history of the language has tended to acquire autonomy in recent years, although the aim should not be to dispense with literary history but to establish the appropriate links with it.

Key words: History of Language, History of Literature, Sociology of Language, Romance Linguistics, Catalan Linguistics.

es es es

\section{INTRODUCCIÓ}

La relació entre la disciplina història de la llengua i la disciplina història de la literatura ha estat una relació de subordinació, tant des del punt vista conceptual com metodològic. La primera ha estat subordinada a la segona. August Rafanell (2020: 279), fent-se ressò d'aquesta situació, s'ha referit críticament a l'habitud de mirar el català pretèrit "com un transsumpte de la història literària». No és que els historiadors de la literatura hagin sotmès intencionadament els historiadors de la llengua als seus plantejaments i mètodes, sinó que els fets, per circumstàncies diverses, han anat d'aquesta manera. En aquest article ens proposem, d'una banda, ajudar a explicar les raons d'aquesta subordinació i, de l'altra — molt més breument—, intentar valorar si en l'actualitat la història de la llengua s'ha anat deslliurant d'aquesta subordinació $i$, en conseqüència, mirar de fer alguna aportació sobre quins haurien de ser els camins per a una relació, diguem-ne, igualitària.

En els apartats 2 i 3 tractem de les circumstàncies i els esdeveniments històrics que han perfilat la situació de subordinació a què ens hem referit. L'apartat 4 té com a tema les contingències metodològiques i pràctiques de les dues disciplines, atès que aquestes contingències també expliquen per què la relació ha anat d'una determinada manera. I en l'apartat 5 reflexionem breument sobre l'estat actual de la matèria. L'espai ens impedeix iniciar l'article amb una exposició sistemàtica del concepte d'història de la llengua en què recolza el treball, però ens sembla que n'hi haurà prou si indiquem que la nostra referència és la caracterització i l'enquadrament que n'ofereixen Nicolás (1998) i Ferrando \& Nicolás (2011: 19-42), que d’altra banda no s’allunyen de les assumpcions teòriques d'altres eminents historiadors de la llengua catalana com Modest Prats, Josep M. Nadal, August Rafanell o Francesc Feliu. 


\section{LES CONSTRICCIONS HISTÒRIQUES (I)}

Per a la tradició europea, almenys des del Renaixement, la importància social i cultural d'una llengua depenia de la consistència de la literatura escrita en aquesta llengua. Sense literatura, la llengua no tenia valor ni interès. Sense literatura no hi havia llengua. Com afirmava Pietro Bembo (1966 [I525]: 28), «non si può dire que sia veramente lingua alcuna favella che no ha scrittore». Amb aquest plantejament, la tasca de redactar una història de la llengua s'identificava de fet amb la tasca de redactar una història de la literatura (una història del bon ús de la llengua). A més, es considerava que els idiomes podien ser avaluats en funció de la seva suposada perfecció, i les obres literàries constituïen llavors les fites que mostraven la concreció del grau de perfecció a què «havia arribat» una llengua: una història lingüística era, doncs, la consignació cronològicament ordenada dels "progressos» que la llengua mostrava per mitjà dels textos literaris (és cert que els idiomes també es valoraven si havien estat usats per reis, cabdills i papes, o si s'havien fet servir en codis legals o textos religiosos importants, però aquest fet no contradiu el que acabem de dir, perquè, com se sap, la història de la literatura no ha tingut normalment problemes a l'hora d'incloure en el seu àmbit d'estudi compilacions legislatives, juraments feudals, sermons, cròniques històriques, tractats mèdics, epistolaris i fins i tot memòries sobre el progrés de l'agricultura — tornarem sobre aquest punt més endavant). ${ }^{1}$

Aquest enfocament és el que trobem en una obra del segle xIx com la Historia de la lengua y de la literatura catalana (I857), de Magí Pers i Ramona, que fa correspondre, en línies generals, el "progrés» de la llengua amb el "progrés» de la literatura. Com s'esdevé en altres obres que, des del segle xvi, es publicaven a Europa, no hi ha una separació conceptual clara dels dos elements del sintagma lengua y literatura. No és que Pers i Ramona pensi que els fets polítics no tinguin influència en la història de les llengües, sinó que la influència que tenen pesa de la mateixa manera en la llengua i en la literatura, com s'observa en aquest comentari sobre la unió dinàstica d'Aragó i Castella:

Esta circunstancia [la unió d'Aragó i Castella] merecía fuese notada, porque ella nos revela un principio de decadencia para la literatura catalana, y explica el porque el idioma catalán, dejando de ser lo que era, y de espresar con la misma exactitud los cambios en las costumbres, así en la práctica de las artes como de las relaciones sociales, cayó del rango que habia ocupado, y fué á colocarse lentamente entre los varios dialectos que todavía se hablan en nuestra Península (Pers i Ramona 1957: 16I).

I. Vegeu altres comentaris en la línia del que indiquem en aquest paràgraf a Nicolás (I998: 31, 33, 47-48, 259).

Caplletra 71 (Tardor, 2021), p. 201-217 
Es poden adduir moltes mostres d'aquesta «solidaritat» conceptual, però l'exemplificarem amb dues citacions breus. El 1845 Émile de Laveleye, en la Histoire de la langue et de la littérature provençales, afirma que la «langue et la littérature de la Provence sont les premières nées en Europe dans l'ère nouvelle qui commence» (Laveleye I845: II). Pocs anys abans, George C. Lewis, parlant de Raynouard, deia: «He conceives that the Romance language, formed from the corruption of the Latin, was common to all the countries of Europe in which the Latin had been spoken, and is preserved in a pure form in the Poetry of the Troubadours» (Lewis 1939: 4). Pertanyen al mateix marc cultural les Recherches historiques sur la langue catalane (I824) de Jaubert de Paçà, que precisament Joaquim Molas (1999: 150) considera una de «les primeres síntesis d'història de la literatura catalana». ${ }^{2}$

Una de les tasques que té per fer l'historiador de la llengua catalana és estudiar com es concreta, per a cada període històric, aquesta valoració de la llengua mediatitzada per la visió de la literatura. Es tracta d'una feina que no es pot fer en un article com aquest, lògicament, però, a tall de suggeriment, ens sembla que caldria examinar si un eslògan com «Ramon Llull, creador del català literari» no ha impedit una aproximació més objectiva al català escrit dels segles XIII-XIV. O si la incapacitat del Noucentisme per escriure una història de la llengua catalana no té a veure, precisament, amb el rebuig "corporatiu» de la literatura del segle XIX — i, per tant, de la llengua com a realitat històrica. ${ }^{3}$

Lúnic àmbit de la reflexió històrica al voltant dels idiomes que quedava al marge, relativament, de la tutela de la literatura era el que tenia a veure amb l'origen $\mathrm{i}$ parentiu de les llengües - i, de manera específica, de les llengües que avui anomenem romàniques-, un àmbit que va generar en els segles XVII, XVIII i XIX densos discursos i grans debats - en general, amb una alta dosi d'especulació- i en el qual es posaven en joc dades i enfocaments que no sols provenien de la història de la literatura, sinó també d'àrees del saber com la història, l'arqueologia, la geografia, la psicologia, la religió o la teologia. Però en rigor és problemàtic que tots aquests treballs al voltant dels orígens dels idiomes i de les seves relacions de parentiu — $\mathrm{i}$, sobretot, al voltant

2. En el XIX català només hi ha una curiosa excepció, que és La lengua catalana considerada históricamente (I858), d'Antoni de Bofarull, un treball que recorre sobretot a referents polítics per avaluar la vitalitat històrica de la llengua (tot i que, també curiosament —almenys «curiosament» en relació amb el propi discurs_, quan projecta aquesta vitalitat de cara al futur, la restringeix a l'àmbit de la literatura).

3. No anirem més enllà, com hem dit, però el Noucentisme — se’m perdonarà la provocació— potser no es va interessar en la redacció d'una història del català perquè no li calia; la història de la llengua catalana ja s'allotjava en l'obra de Josep Carner, com declarava Carles Riba el I92I: «pel seu estil passa tota la història del català, no feta, sinó fent-se en curs de creació» (citem de Jordi Malé 2007: 85). 
de la qüestió que més atenció rebia, que era si el provençal (o la llengua "romana») provenia o no del llatí i era o no, al seu torn, la «mare» de les altres llengües romàniques - puguin adscriure's pròpiament al gènere discursiu que anomenem història. En general, no pretenien ser la narració sistemàtica, ordenada d'acord amb l'eix temporal, de les vicissituds d'una llengua o d'un grup de llengües, sinó que consistien en l'articulació d'arguments per resoldre un problema relativament concret i, precisament, «anterior» a la història de cada llengua: el de la preeminència quant a l'origen. Sigui com sigui, no és sobrer assenyalar que fins i tot aquest àmbit de reflexió històrica té, en el fons, una estreta relació amb la literatura: és la infinita fascinació que va exercir la lírica dels trobadors medievals en els escriptors i erudits europeus d'aquests segles el que hi ha a l'origen d'aquests debats (una poesia amb un grau alt de perfecció, que es concebia que anava lligada a una llengua amb un alt grau de perfecció, i tenia sentit llavors que d'aquesta llengua «més perfecta» se'n derivessin les altres). És en aquest marc que hem de situar la singular obra Història de la llengua catalana d'Antoni de Bastero, escrita als anys trenta del segle Xviı i llavors no publicada, que ha estat qualificada com la primera història del català (i que defensava, precisament, que el català era aquest primer idioma romànic). ${ }^{4}$

\section{LES CONSTRICCIONS HISTÒRIQUES (II)}

Amb l'aparició, a partir del primer terç del segle XIX, de la lingüística romànica, el panorama va canviar parcialment. La lingüística romànica té des dels seus orígens una orientació historicista. El seu fruit convencional són les gramàtiques històriques. I les gramàtiques històriques consignen la història d'un canvi lingüístic: del llatí vulgar a les llengües neollatines. La lingüística romànica atorga rigor i objectivitat a l'anàlisi del canvi lingüístic, i hauria pogut contribuir, així, a dotar la història de la llengua d'una maduresa que la fes més autònoma en relació amb la història de la literatura. Però de fet no va ser així. En realitat, la gramàtica històrica —i no és casualitat que sempre es va resistir a autodenominar-se història — s'instituïa principalment com a gramàtica. En la gramàtica històrica l'eix històric és l'instrument que ordena i relaciona les formes lingüístiques, que són l'objecte de la descripció. Tot i que sembli contradictori, en la gramàtica històrica no hi ha, pròpiament, interès per la història com a tal (hi ha interès pel canvi, que no és el mateix). Encara més: la voluntat de constituir-se

4. L'obra de fet no va arribar a un estadi de redacció definitiva. Ha estat editada modernament, el I997, per Francesc Feliu (Bastero 1997).

Caplletra 71 (Tardor, 2021), p. 201-217 
Jordi Ginebra Serrabou

La relació entre història de la llengua i història literària

en un saber homologable a les disciplines considerades científiques va provocar un gir immanentista que va tendir a deixar de costat les explicacions amb continguts socials, psicològics o històrics. Però, alhora, d'alguna manera, va «ocupar» el terreny de la reflexió històrica en matèria de llengua $i$, fins a cert punt, va deslegitimar qualsevol altra mena d'aproximació històrica a les llengües. Com a resultat va deixar la història de la llengua a la deriva, i per això Nicolás (1998: 3I) ha escrit, parlant d'aquest període, que la història de la llengua era un concepte "escassament definit».

La lingüística romànica — la gramàtica històrica - no va ajudar, doncs, a fer que la història de la llengua, com a disciplina, adquirís referents i mètodes específics $\mathrm{i}$ es «deslliurés» — en la mesura que se n'havia de deslliurar — de la pauta de la història literària. En cert sentit encara li ho va posar més difícil, no sols per les raons que acabem de donar. Perquè, d'una banda, la lingüística romànica es presentava -i va ser percebuda així- com una activitat científica, positivista, aliena a les consideracions valoratives que no procedien de la metodologia objectiva de la mateixa disciplina. Però, de l'altra, tampoc no es va saber alliberar, a l'hora d'establir la classificació de les llengües i els dialectes, del criteri de la importància literària. Com se sap, fins i tot figures tan rellevants de la romanística com Diez o Meyer-Lübke van assignar a la literatura un paper important a l'hora de determinar la condició de llengua d'una varietat lingüística concreta. Si s'acceptava aquest punt de vista -i s'acceptava-, és lògic que l'estudiós que volgués escriure la història d'una llengua s'apressés a reunir material literari, ja que, altrament, resultaria que el que feia no era redactar la història d'una llengua (sinó, a tot estirar, la història d'un dialecte, una parla o una varietat). ${ }^{5}$

I encara hi ha una altra qüestió. S'ha afirmat més d'una vegada que el naixement de la lingüística històrica en general i de la lingüística romànica en particular no pot desvincular-se de la irrupció del moviment romàntic (Munteanu 2005: 63-64). El Romanticisme havia desvetllat l'interès pel passat medieval (el moment de l'origen de les llengües romàniques) i per les parles rurals, de grups i comunitats poc «contaminats» per la lletra impresa i la cultura urbana. Això va menar a la convicció, assumida per certs lingüistes i romanistes (en contradicció evident amb el que s'ha assenyalat al paràgraf anterior), que totes les llengües —o fins i tot que totes les "parles»— tenien el mateix valor i dignitat, amb independència de la seva relació amb una determinada

5. La lingüística romànica, doncs, no va ser coherent amb el punt al qual el seu propi mètode analític la feia arribar, que és que no era possible fer una classificació científicament fonamentada del contínuum lingüístic romànic, conclusió que ja va fer pública Hugo Schuchardt el I870 a la conferència Über die Klassifikation der romanischen Mundarten (text no editat fins al 1900), però que de fet, amb excepcions, mai no es va acabar de tenir en compte en els manuals de la disciplina. Vegeu també Müller (1983), i unes reflexions semblants a les nostres a Nadal (I995). 
tradició literària. És coneguda l'afirmació de Max Müller (I86r: 23) —al marge que ell no fos de fet romanista— que un dialecte que no hagi produït literatura és tan important com la poesia d'Homer o la prosa de Ciceró. Aquesta idea — que podríem qualificar, en el seu moment, de revolucionària - conduïa, lògicament, a la possibilitat de plantejar-se que una història de la llengua no havia de ser, principalment, una història de textos literaris. Però, en la pràctica, s'enfrontava a problemes difícils de resoldre. En primer lloc, com acabem de dir, a la psicologia dels mateixos investigadors. Es podia defensar aquesta idea i alhora la contrària (encara que només fos per raons "pràctiques» lligades a l'statu quo del món acadèmic i a les circumstàncies socials i polítiques en què es desenvolupava - i es desenvolupa - l'activitat científica en l'àmbit de les ciències humanes). I, en segon lloc, al problema que una història d'una llengua sense literatura (o una història d'una llengua sense el recurs a la literatura) era una història sense dades, sense documentació. Potser era una història impossible. Si no s'historiaven les fites literàries d'una llengua, ¿què se'n podia historiar? ¿Què hi havia? ¿Què se'n sabia, de les vicissituds temporals d'aquell idioma? No ens estendrem més sobre aquest punt, però convé indicar ara que si, d'una banda, aquest problema va desencadenar la intensificació de la recerca comparatista amb el mètode deductiu de cara a la reconstrucció de llengües antigues i d'estadis antics de llengües vives — i la lingüística indoeuropea va ser el fruit més emblemàtic d'aquesta orientació-, de l'altra no va permetre - $\mathrm{O}$, almenys, no va facilitar—, per raons pràctiques, l'elaboració d'estudis d'història lingüística (sobretot de grans panorames i d'obres de síntesi) coherents amb la idea de la dignitat de les llengües sense literatura.

Per acabar aquest apartat ens referirem breument a una altra circumstància que, aproximadament des del darrer terç del segle XviII, també ha contribuït a relacionar estretament la història de la llengua amb la història de la literatura; que les ha relacionades i que també — ens sembla — ha ajudat a subordinar la primera a la segona, encara que això potser no és tan evident. Com se sap, la cristal.lització de l'estat nacional contemporani va implicar l'homogeneïtzació cultural per la via de la creació del que es va anomenar cultura nacional, un artefacte que alhora serveix per legitimar ideològicament aquest estat nacional. Un element clau de la cultura nacional ha estat la literatura convertida en institució al servei de la cohesió identitària i en agent prominent de l'organització social: la literatura nacional (Even-Zohar 1994, Fox 1998, Moreira da Rocha 20I6). Un altre element clau de la cultura nacional ha estat la relectura dels fets del passat (d'abans d'existir la nació contemporània), ordenant-los d'acord amb un curs històric específic, el de la nació: la història nacional (Moreno Alonso 1999-2000). I de la intersecció d'aquests dos elements en neix la història de la literatura nacional. Un tercer element en joc ha estat, naturalment, la llengua nacional. 
Nombrosos autors han posat en relleu la funció i el valor de la llengua nacional en la construcció de les nacions contemporànies (vegeu, entre altres, Balibar \& Laporte I974, Murgades 1994, Caussat \& altres 1996, Feliu \& Juher 1999, Barbour \& Carmichael 2000, Fabeiro 2004). ¿Per què diem, però, que la història de la llengua nacional se subordina a la història de la literatura nacional? Aquesta és una qüestió que demanaria un estudi extens, i el que afirmarem ara s'ha de considerar que té caràcter de temptativa. Sense idioma nacional no hi ha literatura nacional, evidentment, però cal tenir en compte que la llengua nacional que serveix de vehicle a la literatura nacional és una llengua prèviament seleccionada $i$ «empaquetada» d'acord amb uns formats literaris. I, d'altra banda, cal tenir present que la literatura mostra més clarament la «unitat» $\mathrm{i}$ «indivisibilitat» de la nació: cada nació construeix la seva literatura nacional exclusiva, encara que pot assumir com a nacional una llengua compartida amb altres nacions, $\mathrm{i}$ encara que pot resultar que assumeix com a nacional més d'una llengua. És la necessitat de construir literatures nacionals el que problematitza l'opció d'estudiar les obres literàries escrites en una determinada llengua com un tot unitari, conceptualment homogeni, independent de la seva adscripció nacional, atenent només al fet d'haver estat escrites en un mateix idioma. ${ }^{6}$ La literatura, finalment, ofereix més joc per a les concrecions simbòliques i per a la litúrgia de la memòria col-lectiva, com ara la possibilitat d'entronitzar, per exemple, el poeta nacional. ${ }^{7}$

I un últim apunt. Plantejar-se les llengües en termes literaris és una estratègia — potser no sempre conscient - per fer oblidar el caràcter fortament coercitiu dels usos lingüístics. Perquè la literatura —quan convé- pot ser presentada com una realitat que pertany al món amable i «innocent» de l'art, de les opcions culturals, de les expansions lúdiques de l'esperit. L'espanyol, per exemple, és la lengua de Cervantes, i no pas, posem per cas, la lengua de la Guardia Civil. ¿Què podem tenir en contra d'un escriptor tan insigne? Si la història de la llengua és una història lligada a les grans figures literàries (que, d'altra banda, se suposa que sorgeixen de manera imprevisible, d'acord amb els capricis del geni i la inspiració), ¿com podrem ser conscients que el

6. Aquesta matèria és certament més complexa del que potser es dedueix dels nostres comentaris, i ha suscitat, durant gairebé dos segles, abundants debats i controvèrsies. Per a la qüestió de la literatura nacional de les nacions que comparteixen llengua amb altres nacions, vegeu, per exemple, centrada en el cas del francès, l'anàlisi de Combe (20I3). Per a la qüestió de la literatura nacional de les nacions que tenen més d'una llengua institucional, vegeu, per exemple, centrada en el cas de Suïssa, l'exposició de Gsteiger (I980). Per a Lambert i altres (2005), el «mite de la llengua i la literatura nacionals» és un mite tenaç.

7. La qüestió del poeta (o escriptor) nacional ha estat tractada, per al cas català, per Balaguer (2007, 20I2) i, recentment, per Subirana (2019). Queda encara per fer un seguiment històric de la relació entre els sintagmes llengua nacional i literatura nacional en el cas de la comunitat catalanòfona. 
desplegament històric dels idiomes és el resultat de l'exercici del poder i de la coacció $i$, en bona part, de la violència? I aquesta estratègia funciona, també, en sentit invers: és l'atzar el que ha fet que una llengua no hagi «donat» grans escriptors i que, per tant, sigui un idioma «menor» (o que ni tan sols sigui «llengua»). No s'hi pot fer res. I funciona, també quan convé, amb sentit pervers. Si a una llengua prohibida i minoritzada se li permet el conreu literari (encara que no se li permeti cap altre ús), ja se li concedeix la màxima "dignitat" possible. ¿Quina raó tenen per queixar-se, llavors, els seus parlants? Aquesta orientació va ser seguida, en part, pel franquisme dels anys seixanta, com ha documentat amb rigor August Rafanell: el Consejo Nacional del Movimiento proposava l'«estímulo de la ejercitación literaria y académica del idioma vernáculo», i el mateix ministre Fraga es referia positivament al «cultivo del idioma vernáculo» (Rafanell 20I8: 179, I84).

\section{LA DELIMITACIÓ DE LES DISCIPLINES}

Més amunt ens hem referit al fet que la història de la literatura no ha tingut normalment problemes a l'hora d'incloure en el seu àmbit d'estudi compilacions legislatives, juraments feudals, sermons, cròniques històriques, tractats mèdics, epistolaris i fins i tot memòries sobre el progrés de l'agricultura. Encara que es podria pensar que l'historiador de la literatura recorre a inventariar i analitzar aquest material quan, per a un període concret, no disposa d'obres pròpiament literàries, el fet és que aquesta pràctica ha estat general perquè, almenys en la tradició europea, el mot literatura ha estat sinònim del sintagma textos escrits. La reducció del concepte de literatura per cobrir només la literatura de creació s’opera, com se sap, a partir del Romanticisme. Aquesta qüestió és més rellevant per a la matèria que ens ocupa del que podria semblar, perquè l'estat de coses que acabem de consignar fa que l'estudi de la literatura s'assimili a l'estudi general de tota la cultura escrita. Plantejat d'una altra manera: si la història de la literatura hagués estat vista tradicionalment com a part, posem per cas, de la història de l'art, llavors els textos escrits no literaris —els textos que no adscrivim a la literatura de creació- haurien quedat «alliberats» de la tutela de la història literària, i haurien pogut constituir l'objecte d'estudi d'una disciplina més autònoma. D'una disciplina que no havia de ser necessàriament una història de la llengua (podia ser una història de la cultura, per exemple), però sí una disciplina que proporcionés més espai per a la reflexió —i l'establiment de categories analítiques — al voltant de la funció de la llengua escrita en la formació i estructuració de les comunitats socials; al voltant, en definitiva, de la història de les funcions socials de la llengua —Nicolás (I998: 179),

Caplletra 71 (Tardor, 2021), p. 201-217 
Jordi Ginebra Serrabou

La relació entre història de la llengua i història literària

des d'una altra òptica, també es refereix als resultats que la disciplina podria obtenir, o podria haver obtingut, endinsant-se en la història cultural.

Sigui com sigui, la servitud que la història de la llengua ha mostrat en relació amb la història de la literatura té a veure també amb factors, diguem-ne, estructurals i pragmàtics de les disciplines. El primer és que, de fet, tant la història de la llengua com la història de la literatura s'enquadren $-\mathrm{o}$, sobretot, s'han enquadrat tradicionalment - en una àrea de coneixement més àmplia, que és la filologia. El terme filologia de vegades s'utilitza com a simple terme neutre per designar en conjunt els estudis sobre llengua i literatura (aquest és el sentit que té quan parlem, per exemple, d'una "facultat de filologia»), però d'altres vegades —o potser sempre, d'una manera latent - la filologia és entesa com l'anàlisi dels textos (sobretot dels textos antics) i la interpretació de la cultura a la qual s'accedeix per mitjà d'aquesta anàlisi; en el benentès, a més, que la tradició literària és la part més important d'aquesta cultura a què s'accedeix i que es vol conèixer i ordenar. En aquest marc, els estudis lingüístics són sobretot una ciència auxiliar de la filologia $i$, en definitiva - doncs-, de la història de la literatura (i, aquí, l'expressió estudis lingüistics també inclou els estudis d'història lingüística). El segon factor és que el professional o l'estudiós consagrat a aquestes matèries ha estat generalment — tot i que avui ja no és així- un especialista dedicat alhora a totes dues disciplines. Entre altres raons perquè, quan aquestes disciplines es normalitzen com a activitat universitària — sobretot a partir de la institucionalització de les matèries en la universitat alemanya del segle XIX-, ho fan "en comandita»: l'estudi de les llengües queda emplaçat amb l'estudi de la literatura. I aquesta societat en comandita, per totes les raons adduïdes fins ara, no resulta paritària (potser també perquè la literatura, per la seva mateixa naturalesa, té més impacte social, i l'esforç que l'estudiós dedica a qüestions literàries té més audiència i més repercussió - $\mathrm{i}$, en conseqüència, de vegades també reporta, en l'esfera personal, més beneficis materials). De fet, en relació amb els estudis que tenen com a objecte la llengua i la literatura, la màxima separació a què s'ha arribat avui a les universitats (i més en uns països que en altres) és a la separació entre departaments de teoria literària i departaments de lingüística general. Però quan l'objecte té cognoms (francès, alemany, català, etc.) és difícil — tot i que hi ha excepcions- que les matèries no siguin vistes com una realitat unitària.

El tercer factor, lligat lògicament als anteriors, és que la quantitat (i, de retruc, la qualitat) d'esforç i de feina esmerçada en l'estudi de la història de la literatura ha estat, almenys en la part del món que ens afecta, molt superior a la quantitat d'esforç i de feina dedicada a l'estudi de la història de la llengua. I aquí hi ha una altra raó que ho explica. Estudiar literatura ha significat —almenys, hi insistim, en aquesta part del 
món- estudiar història de la literatura. En canvi, estudiar llengua no ha significat estudiar història de la llengua. No hi ha simetria. La història literària és el plat fort dels estudis de literatura; però la història lingüística és una part petita dels estudis de llengua. En qualsevol universitat dels Països Catalans els professors que treballen en l'àmbit de la història de la literatura catalana són molt més nombrosos que els que treballen en l'àmbit de la història de la llengua catalana. ${ }^{8}$ És normal, per tant, que el conjunt de reflexions, aportacions, dades, assoliments i síntesis relatives a la història de la literatura sigui molt superior al corresponent conjunt relatiu a la història de la llengua. És per això que avui hi ha publicades grans síntesis col-lectives de referència d'història de la literatura catalana, i que no en tenim d'història de la llengua catalana. (De fet, si parlar de relacions vol dir també examinar els contrastos, és lògic que fem ni que sigui una referència breu al fet que resulta remarcable que no hi hagi, en una comunitat cultural que declara emfaticament el valor essencial de la llengua pròpia com a constituent de la seva identitat col-lectiva, cap obra paral.lela, en l'esfera de la història lingüística, a la Història de la literatura catalana de Martí de Riquer, Antoni Comas i Joaquim Molas, veritable «estructura d'estat» — i se'm perdonarà la concessió a una expressió de moda. $)^{9}$

Finalment, el desenvolupament — i el creixement quant a prestigi- de la lingüística com a ciència sincrònica (la fonologia, la teoria sintàctica, la pragmàtica i l'anàlisi del discurs, la lingüística aplicada, etc.) potser també ha contribuït a dificultar que es desplegués amb més força la història de la llengua, i l'ha arraconada a una posició marginal dins els estudis lingüístics. I potser n'ha marginalitzat els estudiosos. Avui no tenim cap problema a denominar lingüista la persona que treballa en fonologia o en sintaxi. ¿¿Direm que l'historiador de la llengua és també un lingüista? No s’ha produït —ens sembla, però aquest és un terreny que trepitgem amb cautela - un fenomen paral.lel en l'àmbit literari. L'especialista en teoria de la literatura, en litera-

8. Naturalment, l'afirmació que estudiar literatura ha significat sobretot estudiar història de la literatura és merament empírica, i no expressa cap posició sobre si això és el que hauria de ser, que no és el tema d'aquest article. El debat sobre la qüestió de si l'enfocament històric ha de ser el principal mètode d'estudi de la literatura no és ben bé nou. Pot consultar-se Rodríguez Gutiérrez (2004).

9. Per a Josep Murgades (I994: I80), els volums de l’obra de Riquer, Comas i Molas són una «baluerna imposant» que s'erigeix en «al-legat de primer ordre contra les pretensions de la historiografia de la literatura espanyola» d'incorporar la producció literària en català com a simple apèndix exòtic. Ara hauríem d'afegir a aquesta caracterització la nova Història de la literatura catalana coordinada per Àlex Broch. La nostra observació no pretén en absolut menystenir les importantíssimes síntesis de Manuel Sanchis Guarner (I980), Josep M. Nadal \& Modest Prats (1982, 1996), Antoni Ferrando \& Miquel Nicolás (201I) i fins i tot la de Pere Marcet (1987). Però no són treballs equivalents als anteriors — en general tampoc no ho pretenien, com es desprèn, per a la penúltima de les obres esmentades, d'una frase del mateix Nicolás (20II: I07).

Caplletra 71 (Tardor, 2021), p. 201-217 
Jordi Ginebra Serrabou

La relació entre història de la llengua i història literària

tura comparada, en mitocrítica o en crítica feminista — posem per cas - potser ha guanyat prestigi acadèmic en els darrers anys, però no ha residualitzat l'historiador de la literatura.

\section{LA QÜESTIÓ AVUI}

L'any 1995, amb unes paraules que cal interpretar — almenys en part — com una conseqüència de tot el que hem anat descrivint fins ara, Modest Prats (I995: 58) va fer l'afirmació següent: "no sabem gairebé res de res de la història de la nostra llengua». És una afirmació contundent que ha estat sovint citada i comentada posteriorment. El que ara ens interessa destacar, però, és que en el passatge en què s'insereix aquesta sentència hi pesa de manera notable la referència a la literatura. Prats hi declara, així, que «ens hem d'acontentar amb aproximacions fragmentàries, més o menys intuïtives $\mathrm{i}$, en tot cas, tributàries de la història literària» $\mathrm{i}$, més endavant, afegeix que funcionem «en el millor dels casos, amb uns esquemes elaborats pels historiadors de la literatura que compten —aquests, sí- amb una tradició prou sòlida i diversa» (Prats 1995: 58).

Avui, l'avinentesa dels vint-i-cinc anys de l'afirmació de Prats ens convida a fer un nou balanç. Un de més general, que no correspon a aquest article, i un de més específic, que sí: ¿̨ón avui les nostres aproximacions a la història de la llengua tributàries encara de la història literària i els nostres esquemes encara deutors dels que elaboren els historiadors de la literatura?

El primer comentari que caldria fer és que la qüestió avui no és tant desvincular la història de la llengua de la història de la literatura sinó intentar establir quina és la relació adequada entre aquestes dues disciplines. Perquè, d'una banda, totes dues activitats acadèmiques han tingut — $\mathrm{i}$ tenen — problemes i limitacions comuns. Sobretot si parlem de la història de literatura i de la història de la llengua catalanes. I, per tant, pot ser convenient no desvincular l'una de l'altra a l'hora de mirar de superar-los. Per exemple, l'any 1999 Joaquim Molas, fent-ne una síntesi valorativa, assenyalava, en comparació amb l'estudi d'altres literatures europees, tres problemes específics de l'estudi de la literatura catalana. Tres problemes antics — que ell feia venir de la Il-lustració — que n'havien retallat l'ambició i la incidència. Eren la identificació de literatura amb text escrit, la condició plurilingüe del patrimoni literari propi (català, provençal, llatí, castellà) i l'autonomia/independència del patrimoni de cada una de les regions que configuren el domini lingüístic (Molas I999: I49). Són problemes que afecten igualment la història de la llengua (al primer dels quals ja hi hem al.ludit), i per tant, pot ser adequat ajuntar esforços per resoldre'ls. De l'altra, reclamar autonomia 
per als esquemes interpretatius dels historiadors de la llengua no vol dir que s'hagi de desatendre el treball teòric i metodològic de la història literària. Així, un dels assoliments més destacats de la història de la llengua catalana dels darrers anys, que ha estat el progressiu abandonament de la periodització Decadència/Renaixença, ha estat propiciat precisament pels historiadors de la literatura (Ginebra 1999: 17). Es tracta d'un exemple d'aportació positiva. El que convé, doncs, simplement, és substituir la subordinació acrítica per les sinergies i la simbiosi. (Cal evitar també l'excessiva distància mental i factual entre estudiosos de la llengua i estudiosos de la literatura, una distància que segurament cal considerar negativa.)

L'examen dels estudis d'història de la llengua catalana dels darrers vint-i-cinc anys fa concloure que avui, en general, es tendeix a l'elaboració d'un discurs més autònom en relació amb la història de la literatura. Per exemple, no és una anècdota que un dels darrers manuals de divulgació de la disciplina, l'obra de Brauli Montoya (20I8), posi com a títol de l'últim capítol del llibre — que tracta dels segles XIX-XXI"La represa interrupta», un títol impensable en un manual equivalent d'història de la literatura catalana. És cert que hi ha encara tics i rutines fortament arrelats, però avui els historiadors de la llengua se serveixen cada vegada més - i en certs casos ja abans de la data de 1995- d'uns plantejaments teòrics i d'un utillatge conceptual i analític que mostren la influència positiva de la sociologia, la sociolingüística, la història, la ciència política, l'antropologia social i la psicologia social (i lamentem quel'espai no ens permeti referir-nos explícitament als autors i els treballs que caldria situar en aquesta línia). La realitat contundent dels esdeveniments històrics també ajuda de vegades a fer veure que història de la llengua i història de la literatura han de seguir cadascuna el seu camí. Així, la forta vitalitat de la literatura catalana durant les darreres dècades (almenys pel que fa a producció) no es correspon de cap manera amb la vitalitat, problemàtica, de la llengua. I ens sembla que avui cap historiador de la llengua sostindria que el català té assegurat el futur perquè el 2019 una jove de vint-i-nou anys publica una meravella com Canto jo i la muntanya balla.

La literatura és un àmbit d'ús lingüístic, com són àmbits d'ús, entre altres, la ciència, el lleure, l'administració o el sistema educatiu (i això ens ho ha ensenyat la sociolingüística). Historiar la literatura com a registre lingüístic és certament una de les comeses de la història de la llengua, com ho és historiar la llengua de la ciència, del lleure, de l'administració i del sistema educatiu (tant l'ús de la llengua en aquests àmbits com les formes que s'hi ha usat). La comesa de l'historiador és també determinar quins registres han influït més i de quina manera en les formes generals de la llengua. I també determinar quina ha estat la funció i quin ha estat el pes dels diferents registres a l'hora de crear i consolidar les representacions d'una comunitat al 
Jordi Ginebra Serrabou

La relació entre història de la llengua i història literària

voltant del valor i la categoria del seu sistema lingüístic. Una funció i un pes que han anat variant al llarg del temps. Potser la literatura — i més específicament, la llengua escrita en general - va ser determinant, en el moment que considerem l'origen dels idiomes romànics, per projectar socialment la percepció d'homogeneïtat lingüística que va convertir el contínuum romànic —al qual, com hem vist, es referia Hugo Schuchardt el I870- en un conjunt concret de «llengües». Aquesta és, com se sap, una de les tesis que defensa des de fa temps el professor Josep M. Nadal (vegeu, entre altres, Nadal 1992 i Nadal 1995) - i, post eum et propter eum, un nombre important d'estudiosos. Algú podria adduir, llavors, que, a l'últim, Nadal sosté que la llengua depèn de la literatura, i que potser no calia escriure tantes ratlles per arribar igualment a la concepció que ja tenia, al segle xvi, Pietro Biembo. Però s'equivocaria. Perquè la posició de Nadal no és una posició que estableixi aquesta dependència a priori, d'acord amb un vincle, diguem-ne, ontològic, sinó que és el resultat d'estudiar els mecanismes que van produir els processos, al si de les comunitats medievals, de cohesió interna - i de diferenciació externa. Avui l'historiador de la llengua sap que la literatura no ha tingut sempre la mateixa força de cara a determinar les representacions lingüístiques de les comunitats — sap, per exemple, que a partir de finals del segle XviII en té més l'estat nacional-, i sap, per tant, que la seva feina consisteix a estudiar com canvien i com cristal-litzen històricament aquestes representacions. La història literària pot ajudar-lo molt. Però sense literatura hi ha llengua i, per tant, història de la llengua.

Jordi Ginebra Serrabou

Universitat Rovira $i$ Virgili

jordi.ginebra@urv.cat

ORCID 0000-0002-8426-6548

\section{REFERÈNCIES BIBLIOGRÀFIQUES}

BALAguer, Enric (2007) «Literatura i imaginari nacional», dins Enric Balaguer \& David Paloma, Literatura i imaginari nacional / La llengua que no tenim, Barcelona, La Busca, p. 7-63.

— (2OI2) «El "poeta nacional" com a tòtem», dins Magí Sunyer \& Montserrat Corretger (ed.), Mitologia, simbologia i literatura (I890-1939), Barcelona, Publicacions de l'Abadia de Montserrat, p. I45-165.

Balibar, Renée \& Dominique Laporte (1974) Le Français national: Politique et pratiques de la langue nationale sous la Révolution française, París, Hachette. 
Barbour, Stephen \& Cathie Carmichael (ed.) (2000) Language and Nationalism in Europe, Oxford, Oxford University Press.

Bastero, Antoni de (1997) Historia de la llengua catalana, a cura de Francesc Feliu, Vic, Eumo Editorial.

Bемво, Pietro (1966 [1525]) Prose della volgar lingua. Gli Asolani. Rime, a cura de Carlo Dionisotti, Torí, Utet.

Bofarull, Antoni de (I858) La lengua catalana considerada históricamente, Barcelona, Imprenta Nueva. [Reproduït dins Antoni de Bofarull, Escrits lingüistics, edició a cura de Jordi Ginebra, Barcelona, Alta Fulla, 1987, p. 35-72.]

Broch, Àlex (coord.) (2013-20I8) Història de la literatura catalana, Barcelona, Enciclopèdia Catalana / Editorial Barcino / Ajuntament de Barcelona, 8 vol.

Caussat Pierre, Dariusz Adamski \& Marc Crépon (1996) La langue source de la nation. Messianismes séculiers en Europe centrale et orientale (du XVIII au XX siècle), Lieja, Pierre Mardaga.

Сомве, Dominique (2013) «L'invention des littératures nationales en langue française au XIX ${ }^{\mathrm{e}}$ siècle. Langue, nation, littérature», dins Sarga Moussa (ed.), Le XIX siècle et ses langues, París, Société des études romantiques et dix-neuviémistes. [En línia: <http://etudes-romantiques.ish-lyon.cnrs.fr/langues.html>.]

Even-ZoHAR, Itamar (I994) «La función de la literatura en la creación de las naciones de Europa», dins Darío Villanueva (ed.), Avances en teoría de la literatura: estética de la recepción, pragmática, teoría empirica y teoría de los polisistemas, Santiago de Compostel.la, Universidade de Santiago de Compostela, p. 357-377.

Fabeiro Hidalgo, Patricia (2004) «Estat, nació i llengua a França», Revista de Llengua i Dret, 42 (desembre), p. 203-228.

Feliu, Francesc \& Cristina Juher, ed. (1999) La invenció de les llengües nacionals, Barcelona, Quaderns Crema.

FERrAndo, Antoni \& Miquel Nicolás (20II) Història de la llengua catalana, Barcelona, Universitat Oberta de Catalunya.

Fox, Edward I. (I998) «La invención de España: literatura y nacionalismo», dins Derek Flitter (coord.), Actas del XII Congreso de la Asociación Internacional de Hispanistas: 2I-26 de agosto de 1995, vol. IV, Birmingham, University of Birmingham, p. I-I6.

Ginebra, Jordi (I999) «Problemes de la història social de la llengua dels segles XIX i XX», Caplletra, 27 (tardor), p. I3-2I.

Gsteiger, Manfred (1980) «Littérature et nation en Suisse», Revue de Littérature Comparée, I4, p. 403-4IO.

Lambert, José, Reine Meylaerts \& Michael Boyden (2005) «La lengua de la literatura: la institucionalización por la mediación del discurso», Tonos Digital.

Caplletra 71 (Tardor, 2021), p. 201-217 
Revista Electrónica de Estudis Filológicos, 9, [s. p.] [En línia: <https://www.um.es/ tonosdigital/znumg/estudios/ lengualiteratura.htm>.]

LAVELeYe, Émile de (I845) Histoire de la langue et de la littérature provençales, Brusselles, Imprimerie de Th. Lesigne.

LewIs, George C. (1839) An Essay on the Origin and Formation of the Romance Languages: Containing an Examination of M. Raynouard's Theory on the Relation of the Italian, Spanish, Provencal, and French, to the Latin, za edició, Londres, John Murray.

MaLÉ, Jordi (2007) «"Una llengua en plena ebullició". Els traductors davant el català literari a les primeres dècades del segle XX", Quaderns. Revista de Traducció, I4, p. 79-94.

Marcet, Pere (1987) Història de la llengua catalana, Barcelona, Teide, 2 vol.

Molas, Joaquim (1999) «Els estudis sobre literatura catalana: passat, present i futur», dins Ciència i cultura al llindar del segle XXI: cicle de conferències, Barcelona, Institut d'Estudis Catalans, p. I47-I54.

Montoya, Brauli (20I8) Aproximació a la història social de la llengua catalana, Alzira, Bromera.

Moreira DA Rocha, Luiz Carlos (2016) «Literature and its role in the formation of the nations», Literatura e Sociedade, 22, p. 68-77. [DOI: I0.II606/issn.2237-II84. voi22p68-77.]

Moreno Alonso, Manuel (1999-2000): «Romanticismo e historia nacional», Revista de Historia Contemporánea, 9-IO, I, p. I3-24.

Müllek, Bodo (1983) «Das Katalanische in der Entwicklung des Sprachenkatalogs der romanischen Sprachwissenschaft», dins Miscelllània R. Aramon i Serra, vol. III, Barcelona, Curial, p. 397-4II.

MülLer, Max (I86I) Lectures on the Science of Language, Londres, Longman, Green, Longman, and Roberts.

Munteanu Colán, Dan (2005) Breve historia de la lingüistica románica, Madrid, Arco/Libros.

Murgades, Josep (1994) «Llengua i literatura dins el fenomen nacional», dins Peter Waldman, Joan Francesc Mira \& Josep Murgades, Sobre el nacionalisme, Lleida, Institut d'Estudis Ilerdencs. [Citat de Josep Murgades, Llengua i discriminació, Barcelona, Curial, I996, p. I64-I85.]

NADAL, Josep M. (1992) Llengua escrita i llengua nacional, Barcelona, Quaderns Crema. - (1995) «El concepte d'història de la llengua», dins Sadurní Martí \& Francesc Feliu (eds.), Problemes $i$ mètodes de la història de la llengua, Barcelona, Quaderns Crema, p. 39-75. 
Nadal, Josep M. \& Modest Prats (1982-1996) Història de la llengua catalana, Barcelona, Edicions 62, 2 vol.

Nicolás i Amorós, Miquel (1998) La història de la llengua catalana: la construcció d’un discurs, València / Barcelona, Institut Interuniversitari de Filologia Valenciana / Publicacions de l'Abadia de Montserrat.

- (20II) «Hi ha una història social de la llengua catalana?», Treballs de sociolingüistica catalana, 2I, p. I05-II4. [DOI: I0.2436/20.2504.0I/2.]

Pers i Ramona, Magí (I857) Historia de la lengua y de la literatura catalana, Barcelona, Imprenta de José Tauló.

Prats, Modest (1995) «Contrareforma i Barroc», L'Avenç, I89 (febrer), p. 58-63.

Rafanell, August (2018) «Una rectificació del franquisme sobre el català», dins Carles Santacana (ed.), Quan tot semblava possible... Els fonaments del canvi cultural a Espanya (1960-1975), València, Publicacions de la Universitat de València, p. $177-205$.

- (2020) «[Ressenya de] Brauli Montoya, Aproximació a la història social de la llengua catalana, València, Bromera, 2018», Caplletra, 68 (primavera), p. 279-285. [DOI: I0.7203/Caplletra. 68.16486.]

Riquer, Martí de, Antoni Comas \& Joaquim Molas, dir. (1964-1988) Història de la literatura catalana, Barcelona, Ariel, in vol.

RodríGuez Gutiérrez, Borja (2004) «Historia literaria versus teoría de la literatura. Consideraciones sobre el debate», dins Gonzalo Martínez Camino, Margarita García Casado \& Sean Scurfield (ed.), Encuentro de lenguasy literaturas, Santander, Universidad de Cantabria, p. 239-249.

Sanchis Guarner, Manuel (1980) Aproximació a la història de la llengua catalana, Barcelona, Salvat.

SChuchardt, Hugo (1900 [1870]) Über die Klassifkation der romanischen Mundarten, Graz, [s. e.].

Subirana, Jaume (2019) Construir con palabras. Escritores, literatura e identidad en Cataluña (I859-2019), Madrid, Cátedra. 